\title{
Neurological and neuropsychological effects of cerebral spinal fluid shunting in children with assumed arrested ("normal pressure") hydrocephalus
}

\author{
RICHARD D TORKELSON*, LYAL G LEIBROCK, † JOHN L GUSTAVSON, \\ ROBERT R SUNDELL§
}

\begin{abstract}
From the Departments of Neurology, ${ }^{*}$ Neurosurgery, $\dagger$ and Psychiatry $\ddagger$ University of Nebraska Medical Center and the University of Nebraska College of Medicine§ Omaha, Nebraska
\end{abstract}

SUMMARY Normocephalic children found to have ventriculomegaly during evaluation of longstanding ( $4 \cdot 5-8 \cdot 5$ years) neurological disorder were tested for academic achievement, intellectual quotient and neuropsychological functioning. Radioactive iodinated serum cisternography, pre and post-shunt electrophysiological studies (visual evoked responses, brainstem auditory evoked potentials, sleep electroencephalograms) and radiological studies (skull radiographs computed tomography) were recorded. Four children who have been followed more than one year after insertion of ventricular-peritoneal shunts are presented. All demonstrated improvement in psychometric findings along with some improvement in CT scan and EEG studies. The most marked initial changes were noted on measures of neuropsychological performance, accompanied later by improvement in measures of intelligence. Achievement test scores showed no consistent pattern of change. This sample suggests that there is a group of asymptomatic children with apparent clinically stable (arrested) hydrocephalus in whom abnormal neuropsychological testing indicates the need for cerebrospinal fluid shunting, with subsequent improvement.

One occasionally discovers apparent asymptomatic ventriculomegaly during examination of a child. Although the syndrome of normal pressure hydrocephalus has been recognised in children for some time,$^{12}$ the literature on its diagnosis, treatment and distinction from "arrested" hydrocephalus remains limited. Terms such as "normal pressure hydrocephalus," "occult hydrocephalus," or " compensated hydrocephalus" are generally used to imply that the enlarged ventricles are of clinical importance, and "arrested hydrocephalus" to imply that the ventriculomegaly is no longer of pathological significance. A variety ${ }^{3}$ of clinical and laboratory

\footnotetext{
Address for reprint requests: Richard D Torkelson, MD, Director, Child Neurology, Department of Neurology, University of Nebraska Medical Center, 42nd and Dewey Avenue, Omaha, Nebraska. 68105 , USA.

Presented in Part at the Eleventh Annual Interim Meeting Section of Pediatric Neurological Surgery. American Association of Neurological Surgeons, San Francisco, California, USA, December 10,1982 .
}

Received 7 February 1984 and in revised form 17 December 1984. Accepted 24 December 1984 evaluations have been utilised to help differentiate between these two states and include: changing neurologic findings, calculating excessive cranial growth velocity, noting ventricular angles and lack of air over the convexities on pneumoencephalography, assessing the response to repeated lumbar punctures, finding features on cranial computed tomography (CT) such as periventricular hypodensity or sequential changes in measured volume, utilising radioisotope (RISA) cisternography to evaluate cerebrospinal fluid (CSF) flow and dynamics, employing short term continuous cerebral pressure monitoring, detecting alterations on cerebral blood flow studies, following changes in visually evoked potentials (VEPs) or slow burst activity in serial electroencephalograms (EEG) ${ }^{4}$ using constant rate lumbar infusions to assess CSF absorptive capacity, ${ }^{5}$ and recently servo-controlled variablerate lumbar infusions. ${ }^{\circ}$ While most of these techniques can be of value when they are clearly abnormal, some, such as cranial growth velocity, can be frankly misleading; ${ }^{\prime 7}$ others, such as RISA cisternography, have been demonstrated to have relatively poor sensitivity and specificity; ${ }^{84}$ yet others, 
such as continual short term pressure monitoring, can be faulted as being assessments of the immediate physiological status and possibly not always reflecting the overall chronic state. Ultimately, however, the success or failure of any diagnostic study or studies used in making the decision whether to shunt is the intellectual fate of the patient. ${ }^{17}{ }^{10}$ As the goal is to preserve intellectual functioning, ideally one would like a sensitive neuropsychological assessment that could reliably detect early changes of progressive brain dysfunction, define a particular pattern of dysfunction that correlates with pathological ventricular enlargement, help predict which children would benefit from cerebrospinal fluid diversion and be a sensitive tool to monitor the results of the diversion procedure.

Neuropsychological assessment is a recent facet in the evaluation of children, although these techniques have existed for some time for use in adults. Theoretically, these instruments are designed to measure functions which are more closely allied to brain structure and function than are the more traditional psychological tests." 12 It was hypothesised that since neuropsychological testing measures functions that are more directly mediated by the brain than intellectual or achievement tests, they would be more sensitive both to impairment associated with normal pressure hydrocephalus and the immediate changes that followed surgical alleviation. Alternatively, it was posited that traditional intelligence tests, which are assumed to measure more crystallised and higher integrative cortical functions, would be less sensitive to the neuropsychological deficits and to the immediate and anticipated changes following shunting. Achievement testing, theoretically dependent on training and the learning environment, was thought likely to show the least amount of change after operation.

\section{Methods}

Patients were initially seen by one of the authors (RDT) in a general clinic for evaluation of chronic neurological disorders, none of the patients being referred because of suspected intracranial pressure. When ventriculomegaly was noted on the cranial CT scan, the patients were further assessed with skull radiographs, EEG during wakefulness and sleep, VEPs, brainstem auditory evoked responses, RISA cisternography and a battery of psychological tests including measures of academic achievement, intellectual ability and neuropsychological functioning. As the children were of differing ages, identical psychometric tests could not be administered to every child. Lumbar pressure measurements were made during RISA cisternography and ventricular pressure during shunt placement. The electrophysiological studies, CT scans and psychological tests were repeated at three to six month intervals following surgical correction of the hydrocephalic syndrome.
The Luria-Nebraska Neuropsychological Battery was utilised as the primary neuropsychological measure. This recently developed battery has been extremely effective in the assessment of brain functioning in adult populations." 12 The battery provides an assessment of eleven clinical areas including motor, rhythm, tactile and visual functions; receptive and expressive language abilities; basic writing, reading and arithmetic skills; memory and intellectual processes as well as several other empirically derived scales. The children's revision of this battery has also demonstrated considerable promise in the neuropsychological assessment of youngsters. ${ }^{13}$ The LuriaNebraska Neuropsychological Battery-Children's Revision was developed using age-normed data and takes into account the effects of maturation and learning. Although improvement in actual performance would be expected as a youngster advances in age, test scores on this battery would not change over time. Moreover, test-retest reliability studies have yielded significant results, suggesting good stability and little variance with repeat testing. ${ }^{13}$ Although extensive age-normed data are not available for the two youngest children in this study, applicable items from the battery were administered to provide a baseline measure of performance. The Beery Development Test of Visual Motor Integration and the Finger Tapping Test were also used as neuropsychological indices. The Wechsler Scales, McCarthy Scales, and Peabody Picture Vocabulary Test were employed as intellectual or IQ measures. Four children have been followed for more than a year and are the subject of this paper.

\section{Cases}

Case 1: The oldest patient ( 10.5 years) was referred for evaluation of a reportedly stable left hemiparesis. History was sparse as she had been in multiple foster homes. She became a ward of the state at 18 months of age following inflicted traumatic bilateral subdural hematomas that were successfully evacuated. Currently, her head circumference was at the 50th percentile, height and weight at the 15 th percentile. In addition to "cocktail party" speech, she had a moderate left hemiparesis and spastic diplegia though could ambulate well enough to participate in running games with only moderate difficulty. No history was elicited to suggest episodes of elevated intra-cranial pressure. The case worker who had known her for five years thought her gait had not changed though was concerned about her increasingly poor academic peformance. At the time of shunt placement, her intracranial pressure was thought to be mildly increased, though was not formally measured. Figure 1 shows CT scans before and after shunt insertion. Ventricular size diminished over the next year, but not impressively so.

On initial psychometric testing, the patient showed diffuse organic impairment with deficits in all major areas of neuropsychological functioning. Her performance on intellectual testing was at a levels below which a meaningful IQ could be calculated on either the Peabody or Wechsler scales. Similarly, achievement tests showed performance in reading and writing to be at levels below which standard scores are applicable. Arithmetic was at the low extreme of reliable scores. Given the magnitude and pervasive nature 


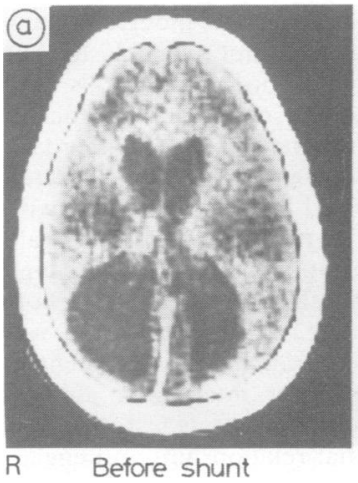

Fig 1 Case 1

of her dysfunction, it was impossible to demonstrate reliable differences between various aspects of neuropsychological ability. On follow-up testing after insertion of a shunt although the patient continued to exhibit a pattern of diffusely impaired functioning relative to normal expectations, with no measurable change on standardised intelligence testing she manifested statistically significant improvement on five of the eleven scales of the LuriaNebraska Neuropsychological Battery and improvement in two others. Her greatest gains were noted on tasks assessing motor and tactile functions; auditory attention, tracking and discrimination; expressive speech and intellectual processes. Although initial follow-up achievement testing revealed no appreciable changes, assessment one year following shunt placement showed gains in reading and spelling. Since the tests are age-normed, these findings suggest that the patient's trend of deteriorating performance has reversed, at least for reading and spelling. The patient's mother has noted increased attention, concentration and on-task behaviour consistent with that which might be expected from the testing results.

Case 2: The second oldest patient ( 8.5 years) was referred because ventriculomegaly had been noted during cervical computed tomography for a single episode of lower neck pain which resolved within 48 hours. She was in the top quartile of her class. Detailed review of systems was unremarkable. Because she was only 32 weeks gestational age at birth and had neonatal hyperthryoidism, she had initially been closely followed and review of her old charts showed that the head circumference had gone from the 3 rd percentile to the 90th percentile in the first 21 months of life, where it stayed. Currently, her head circumference was at the 80th percentile, height and weight below the 3rd percentile. (Her head size could be considered suspicious in view of her short stature, though there was maternal familial short stature.) Pre-shunt neurological examination was normal, including the presence of spontaneous venous pulsations on ocular examination. Figure 2 shows CT scans before and after shunt insertion. One should note the well defined cortical markings on the pre-operative CT. CSF pressure at the time of shunt placement in the semirecumbent position was $150 \mathrm{~mm} \mathrm{H}_{2} \mathrm{O}$.

Initial pyschological testing with this patient showed intellectual functioning in the dull normal range and
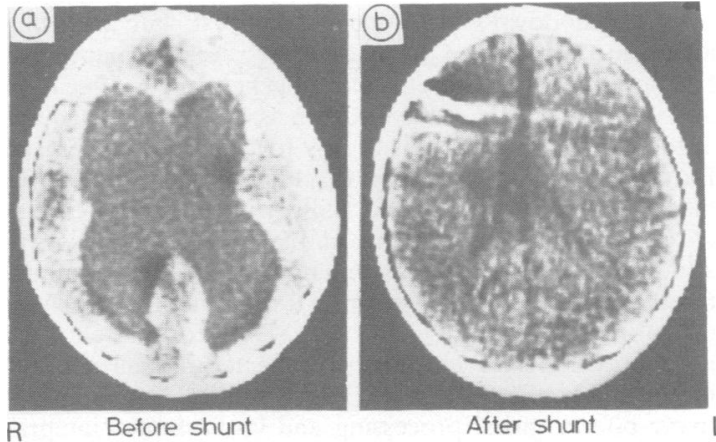

Fig 2 Case 2

academic mastery in the low average range of ability. Neuropsychological evaluation revealed a diffuse pattern of deficits with comparative strengths observed in tactile functions and visual processing skills. There was particular impairment of higher cortical and integrative abilities. Follow-up neuropsychological evaluation showed a pattern of statistically significant improvement in motor functions, auditory attention and discrimination abilities and some areas of rudimentary academic skills and general reasoning processes. Statistically significant changes were not found on the latest standardised intellectual or achievement tests performed nine months after shunt insertion.

Case 3: The third oldest patient ( $5 \cdot 5$ years) was referred for a second opinion to improve control of her left sided focal seizures. Although in the first grade, she was reading at the third grade level. History revealed she had been delivered by elective caesarean section because of cephalopelvic disproportion with birth weight, height and head circumference all greater than the 75th percentile. Currently, height and weight were at the 75th, head circumference at the 98th percentile. She had a left spastic hemiparesis and additional mild spastic diplegia. Figure 3 shows CT scan before and after operation. Postoperatively, the left ventricle is smaller and there is more cortical mantle on the right, though the changes are not striking.

Initial psychometric testing showed this patient functioning in the average range of intellectual ability, as estimated
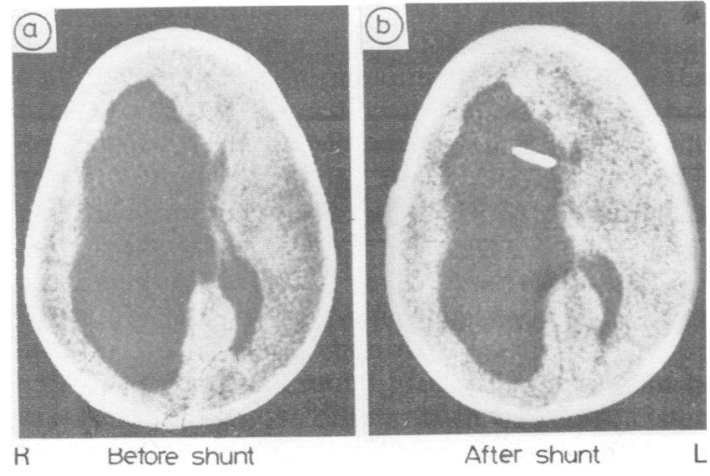

Fig 3 Case 3 
by the Peabody Picture Vocabulary Test, but achieving average to superior on the Wide Range Achievement Test. It is noted that both parents had a background in education and invested considerable effort in assisting her to acquire academic skills. Although norms for the Luria-Nebraska Battery were not available for her age, selected items measuring motor and tactile skills, rhythm and pitch discrimination, visual processing and memory functions were administered from this instrument. She was also administered the finger tapping test and Development Test of Visual Motor Integration. Generally, her performance on the neuropsychological assessment reflected impairment of motor and tactile skills in the left extremity, and comparatively poorer visual processing and visual-motor integration skills than verbal comprehension and reasoning abilities. On post-operative testing, the patient showed a significant gain in IQ though because of a ceiling effect, significant improvement was not recorded on achievement testing. Noticeable improvement was observed in motor coordination, writing and visual-motor integration suggesting greater cerebral integrity. Changes in motor speed or tactile sensation were not apparent in the left hand. Additionally, the patient was observed as more attentive and better able to stay on task compared to initial testing, though this had not been perceived as an area of concern earlier. Complete seizure control occurred after shunting without any increases in her anticonvulsants.

Case 4: The youngest patient ( 4.5 years) was a ward of the state with long-standing stable left hemiparesis who was referred for a pre-adoptive neurological examination. Premature at birth, she had Group B beta streptococcal sepsis and meningitis with a possible intraventricular haemorrhage while in the neonatal nursery. She had meningitis again at $4 \frac{1 / 2}{2}$ months of age. She was reportedly doing well in preschool. Currently, her head circumference was at the 90th, height and weight were greater than the 98th percentile. In addition to "cocktail party" speech, she had a mild left hemiparesis and additional mild spastic diplegia. Figure 4 shows CT scans before and after shunt insertion.

Initial psychological evaluation demonstrated overall functioning in the dull normal range of ability, with a markedly higher Verbal than Performance IQ. As in the previous case, the patient was administered selected items from the Luria-Nebraska Battery and other neuropsychological

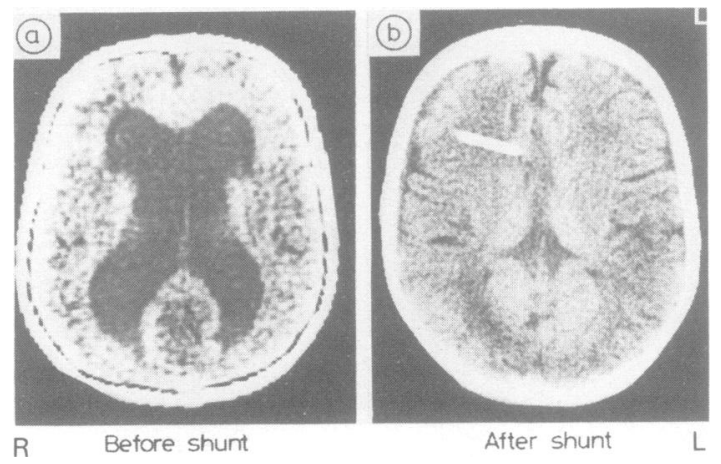

Fig 4 Case 4 measures to record baseline performance, though in many areas normative performances were not available for her age. Evaluations showed visual processing skills and visual-motor integrative abilities consistently deficient when compared to general verbal reasoning and other language mediated functions. Follow up testing demonstrated significant increases in measured intellectual ability with the largest gains recorded in Performance and Full scale IQ. She changed from a classification of dull normal to high average ability overall, and in Performance IQ, from borderline retarded to low average. A similar pattern was noted on the McCarthy scale. Dramatic improvement in visual processing and visual-motor integration abilities were demonstrated on the neuropsychologic tests. She was capable of utilising visuo-spatial relationships and engaging in non-verbal problem solving at a level of significantly better than that seen preoperatively. Visual attention and tracking skills were also seen to increase and there was slight improvement in unilateral motor coordination and speed.

\section{Results}

These children share the common characteristics of: (1) having ventriculomegaly discovered during the evaluation of other problems, (2) demonstrating none of the classic clinical signs of elevated intracranial pressure, (3) having historical evidence of insults that would suggest their ventriculomegaly was long-standing, and (4) completing at least one year of serial psychometric testing following shunt placement. No shunt-related complications have been encountered in the study group.

The study protocol employed traditional neurodiagnostic methods along with standard intellectual assessments and a neuropsychological battery of tests undergoing adaptation to the paediatric population called the Luria-Nebraska Neuropsychologic Battery. Skull radiographs and electrophysiologic studies generally were not helpful (Tables 1 and 2), with the exception of asynchronous asymmetry of sleep spindle activity during sleep EEGs which consistently improved after shunting. In evaluating patients with known past ventriculomegaly who are now being added to the study, we note serial CT scans may show little change over time. Likewise, even with marked intellectual improvement after shunting, as noted by others, ${ }^{15}$ the CT changes may not be impressive.

In table 3 the left hand column summarises the overall changes found using the neuropsychological test batteries. These results were found at the first evaluation performed three months after the placement of the shunts. The Wechsler Scales, McCarthy Scales, and Peabody Picture Vocabulary Test were employed as intellectual or IQ measures. The results of these studies are summarised in the middle column (table 3). Although testing at six to nine 
Table 1 Diagnostic results pre-shunt

\begin{tabular}{|c|c|c|c|c|}
\hline Case & $V E P$ & $E E G$ & Cisternography & $C T$ \\
\hline 1 & $\begin{array}{l}\text { Bilaterally abnormal, } \\
\text { O.S. latency greater } \\
\text { than O.D. }\end{array}$ & $\begin{array}{l}\text { Asynchronous asymmetry of sleep } \\
\text { spindles, diffuse atypical spike and } \\
\text { wave activity with sporadic multifocal } \\
\text { spikes. }\end{array}$ & $\begin{array}{l}\text { Abnormal with } \\
\text { ventricular tracer still } \\
\text { present at } 48 \text { hours. }\end{array}$ & $\begin{array}{l}\text { Ventriculomegaly involving both } \\
\text { lateral ventricles and third ventricle. } \\
\text { Adjacent cortical low density suggests } \\
\text { focal cerebral porencephaly. }\end{array}$ \\
\hline 2 & Normal latencies. & $\begin{array}{l}\text { Asynchronous asymmetry of sleep } \\
\text { spindles and K-complex activity during } \\
\text { sleep recording. }\end{array}$ & & $\begin{array}{l}\text { Ventriculomegaly involving both } \\
\text { lateral ventricles and third ventricle. }\end{array}$ \\
\hline 3 & $\begin{array}{l}\text { Normal latency O.D.. } \\
\text { abnormal latency O.S. }\end{array}$ & $\begin{array}{l}\text { Asynchronous asymmetry of sleep } \\
\text { spindles, decreased voltage over right } \\
\text { hemisphere. multifocal right } \\
\text { hemispheric spikes. }\end{array}$ & $\begin{array}{l}\text { Abnormal pathways. } \\
\text { delayed activity in } \\
\text { right ventricle (up to } \\
48 \text { hours). }\end{array}$ & $\begin{array}{l}\text { Ventriculomegaly involving both } \\
\text { lateral ventricles, right far greater } \\
\text { than left. and also the third ventricle. }\end{array}$ \\
\hline+ & Normal latencies. & $\begin{array}{l}\text { Asynchronous asymmetry of sleep } \\
\text { spindle and } K \text {-complex activity in sleep. } \\
\text { mild slowing. }\end{array}$ & & $\begin{array}{l}\text { Ventriculomegaly involving both } \\
\text { lateral ventricles and third ventricle. }\end{array}$ \\
\hline
\end{tabular}

Table 2 Diagnostic results after-shunting

\begin{tabular}{|c|c|c|c|}
\hline Case & $V E P$ & $E E G$ & $C T$ \\
\hline 1 & $\begin{array}{l}\text { No improvement of bilateral } \\
\text { abnormalities. }\end{array}$ & $\begin{array}{l}\text { Infrequent asynchronous asymmetry } \\
\text { of sleep spindles, multifocal spikes. }\end{array}$ & $\begin{array}{l}\text { Limited improvement of } \\
\text { ventriculomegaly. }\end{array}$ \\
\hline 2 & No change in normal latencies. & $\begin{array}{l}\text { Rare asynchronous asymmetry of } \\
\text { sleep spindles. }\end{array}$ & $\begin{array}{l}\text { Improvement of ventriculomegaly } \\
\text { with normal sized ventricles. }\end{array}$ \\
\hline 3 & No improvement (OS. no change OD. & $\begin{array}{l}\text { Modest improvement of asynchronous } \\
\text { asymmetry of sleep spindles. }\end{array}$ & $\begin{array}{l}\text { Minimal improvement of } \\
\text { ventriculomegaly. }\end{array}$ \\
\hline+ & No change in normal latencies. & $\begin{array}{l}\text { Occasional asynchronous asymmetry } \\
\text { of sleep spindles, no slowing. }\end{array}$ & $\begin{array}{l}\text { Improvement of ventriculomegaly with } \\
\text { normal sized ventricles. }\end{array}$ \\
\hline
\end{tabular}

Table 3 Summary of psychological test results

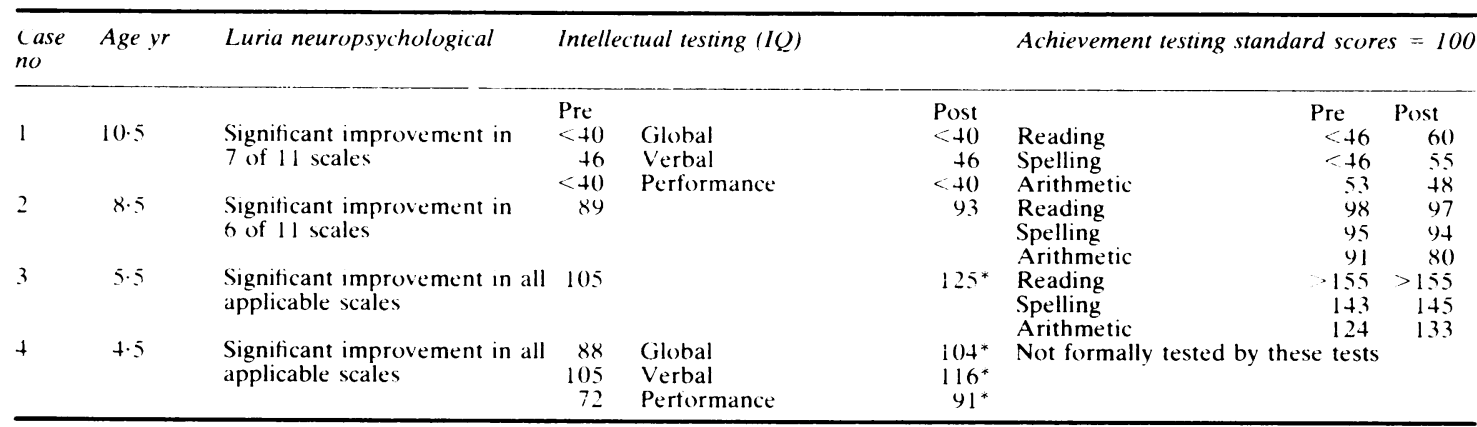

*Significant change

months demonstrated a trend toward increased IQ when it occurred, the findings listed on the table are those obtained one year following the shunt. The Wide Range Achievement Test summarised in the right hand column (table 3 ) provided an assessment of academic performance and are the results obtained at the one year follow-up.

Because of the small sample of subjects, statistical analysis was not applied to the data; however, several trends are apparent on examination of the results. The central hypotheses were largely confirmed. Initial baseline IQ testing and academic achievement testing were normal in the three youngest cases, though all the subjects showed significantly impaired performance on preoperative
Luria-Nebraska Neuropsychological testing. Following surgery, each of the subjects demonstrated immediate and statistically significant improvement in the majority of areas assessed on the neuropsychological testing. Similar increases were not seen immediately on measures of intelligence, though these were found in long-term follow-up. On final assessment, the subject with initially slightly above average $\mathrm{IQ}$ produced a score in the superior range of ability. Of the two in the low average range, one improved her IQ score by a few statistically insignificant points; however, the younger of the two moved to the above average range which is statistically significant. The oldest subject scored initially in the severely retarded IQ range, though because the 
IQ test employed did not measure below 40, we could not be certain that there was no change. Interestingly, this subject did show significant gains on neuropsychological testing suggesting the potential for later increase in IQ since there is a positive correlation between these two measures. Additionally, by adaptive behavioural criteria she is not by strict definition retarded. This fact suggests she once had a much higher IQ. Considering how long she presumably had her normal pressure hydrocephalus, and the apparent slower return the longer the condition persists, more observation time is necessary. For all patients, achievement test scores did not change appreciably. This finding suggests changes in these areas were not directly commensurate with either increasing chronological age or with the improvements noted on the other instruments.

\section{Discussion}

One of the major interests in this investigation was the relative difference in results observed among the various psychometric measures used. Several observations and conclusions were noted regarding the characteristics of the children in this study and the relationships of these characteristics to outcome as measured on the psychological testing. First, subjects who showed the most appreciable gains were those who were not substantially impaired in terms of overall IQ scores to begin with, though each demonstrated a pattern of disparity between verbal and visual-motor performance skills, visual-motor skills being worse than verbal skills. Deficits in visualspatial relationships have long been described in untreated hydrocephalic children, ${ }^{16}$ though admittedly this pattern of difference is not uncommon in the general population and is certainly not unique to children with neurologic conditions.

The second observation is that the two most improved subjects had abnormal neuropsychological findings in the face of normal intelligence. It is most probable that these youngsters had a premorbid higher intellectual potential which was impaired by the normal pressure hydrocephalus. Of note, on the basis of preoperative intelligence testing alone, they probably would not have been referred for neurological evaluation. Importantly, the oldest subject, who demonstrated severe retardation as well as profound neuropsychological deficits, not only showed the poorest follow-up performance but also made the least and slowest relative gains in improvement. Although without a longitudinal study we cannot prove that her ventriculomegaly was the most chronic, the conclusion that the earlier the shunt is placed the better the chance for normal development in patients with simple hydrocephalus has previously been demonstrated in regard to higher achieved IQ. ${ }^{17}$

Third, although few consistent patterns of deficits were noted among the results of the neuropsychological testing, across the sample it was evident that each subject showed difficulties in fine psychomotor functions. These difficulties were not always apparent on gross examination but did show up on the more refined psychometrics. Deficits were typically seen in the performance of rapid, sequential, coordinated movements of the hands, particularly those requiring bilateral coordination. Similar findings have been found in patients with myelomeningoceles and presumed "arrested" hydrocephalus who benefited from shunting. ${ }^{18}$ In another study of shunted 4-9-year-old patients with "uncomplicated" hydrocephalus and subsequent normal sized ventricles, deficits in verbal and nonverbal memory, fine motor speed and coordination, and visual spatial problem solving were found, though a longitudinal study was not done to access how these deficits changed over time. ${ }^{19}$ Short-term and intermediate memory deficits were also common to three of our four subjects.

Fourth, variability or scatter in performance on the neuropsychological subtests was a consistent finding related to improvement. Again, the pattern of strengths and weaknesses among the subjects was not entirely uniform; however, the fact that some areas were intact while others were significantly impaired (suggesting focal effects of the disease process) was associated with a favorable prognosis.

Fifth, it has been reported that preoperative serial testing often shows psychomotor development not keeping pace or even worsening with chronological development in children with myelomeningoceles and normal pressure hydrocephalus who stand to benefit from shunting. ${ }^{18}$ Similar conclusions are probable from a study demonstrating that patients with episodic non-functioning shunts and delays in revisions have significantly lower IQ than those treated promptly, and this was independent of the number of shunt revisions. ${ }^{17}$ Because of the striking abnormalities in the Luria-Nebraska Neuropsychological Battery coupled with the standard neurodiagnostic techniques, our study did not involve pre-shunt serial examinations to verify deterioration in standard IQ tests as we could not ethically justify such a controlled study.

In summary, there is a population of children with enlarged ventricles, with few, if any, clinical complaints. Head circumference may not suggest the underlying pathology, and the child may have performed at or above average intellectual levels for years. Although usually there is some clinical evidence for a mild hyperreflexic diplegia when com- 
paring the reflexes of the upper extremities to the lowers, the diplegia may be absent, subtle, present but non-progressive. The findings of spontaneous venous pulsations, or, as we have found in patients now entering the protocol, monitored pressures that are borderline or infreqently episodically elevated, suggest the pressure changes are not impressive and must be searched for, as has been demonstrated to occur in REM sleep. ${ }^{20}$

One cannot rely on parental reports about the progress of a child suspected of having normal pressure hydrocephalus, as the patient's maturational development, achievement skills, and continuing strengths in verbal abilities and adaptive behaviour make cursory observation or testing unreliable. Simple intelligence testing is frequently non-specific, but the finding of higher verbal than performance IQ coupled with ventriculomegaly on cranial CT scan, should raise strong suspicions of pathological cause and effect. The Luria-Nebraska Neuropsychological Battery adds further diagnostic refinement to psychological testing by more directly assessing brain function and not crystallised functions or achievements. A scattering in subtests with impaired performance in fine psychomotor functions (rapid, sequential, coordinated movements), shortterm and intermediate memory deficits correlates with improvement after shunting. Improvement after shunting is first seen in the Luria-Nebraska Neuropsychological Battery followed later by changes in traditional IQ testing, further strengthening its possible predictive value. Lastly, presumably the longer there is delay in recognition of the pathological state, the greater the impact on the ultimate morbidity. Several children too young (less than four year of age) were not included in this reported series because of the current age limitations of the Luria-Nebraska Neuropsychiatric Battery. Although they also demonstrated improvement in age-normed developmental assessments, efforts are currently underway to extend the age limits of this test downwards to include this imporant group of children

Clearly, the present findings are preliminary in the understanding of the intellectual and neuropsychological aspects of normal pressure hydrocephalus in the paediatric age group. Further longitudinal study in this area with larger samples of subjects are needed and should prove valuable in enabling one to identify patients who stand to benefit from shunting and perhaps provide insight on the manner in which normal pressure hydrocephalus affects intelligence.

\section{References}

' Milhorat TH, Hammock MK: “Arrested" versus normal pressure hydrocephalus in children. Clin Proc Child Hosp Natl Med Cntr 1972;28:168-73.

${ }^{2}$ Milhorat TH. Hydrocephalus and the Cerebral Spinal Fluid. Baltimore: Williams and Wilkins, 1972:182-5.

${ }^{3}$ Schutz H, Fleming JFR, Humphreys RP, Deck JHN, Keith WS. Normal pressure hydrocephalus-high pressure Normocephalus. Can J Neurol Sci 1980;7:211-9.

${ }^{4}$ Hashi K, Nishimura S, Kondo A, Nin K, Jac-Hong S. The EEG in normal pressure hydrocephalus. Acta Neurochir 1976;33:23-35.

${ }^{5}$ Di Rocco C, Caldarelli M, Maira G, Rossi GF. The study of cerebrospinal fluid dynamics in apparently "arrested" hydrocephalus in children. Childs Brain 1977;3:359-74.

- Sklar FH, Beyer CW Jr, Ramanathan M, Clark WK. Servo-controlled lumbar infusions in children, a quantitative approach to the problem of arrested hydrocephalus. J Neurosurg 1980;52:87-98.

' Schick RW, Matson DD. What is arrested hydrocephalus? J Pediatr 1961;58:791-9.

${ }^{8}$ Black PMcL. Idiopathic normal pressure hydrocephalus; results of shunting 62 Patients. J Neurosurg 1980;52:371-7.

' Belloni G, Di Rocco C, Focacci C, Galli G, Maira G, Rossi GF: Surgical indications in normotensive hydrocephalus. A retrospective analysis of the relations of some diagnostic findings to the results of surgical treatment. Acta Neurochir 1976;33:1-21.

${ }^{10}$ Gordon N. Normal pressure hydrocephalus and arrested hydrocephalus. Dev Med Child Neurol 1977; 19:540-3.

"Golden CJ, Purisch AD, Hammeke TA. The LuriaNebraska Neuropsychological Battery-A Manual for Clinical and Experimental Uses. Lincoln: University of Nebraska Press, 1979.

${ }^{12}$ Golden CJ, Hammeke TA, Purisch AD, et al. Item Interpretation of the Luria-Nebraska Neuropsychological Battery. Lincoln: University of Nebraska Press, 1982.

${ }^{13}$ Golden CJ. Luria-Nebraska Battery: Theory and Formulation. In: Hind GW, and Obrzut JE, eds. Neuropsychological Assessment and the School Age Child. New York: Grune and Stratton, 1981.

${ }^{14}$ Plaisted JR, Gustavson JL, Wilkening GN, Golden CJ. The Luria-Nebraska Psychological Battery-The Children's Revision: theory and current research findings. J Clin Child Psychol 1983;12:13-21.

is Jacobs L, Kinkel W. Computerized axial transverse tomography in normal pressure hydrocephalus. Neurology (Minneap) 1976;26:501-507.

${ }^{16}$ Miller E, Sethi L. The effect of hydrocephalus on perception. Dev Med Child Neurol 1971;Supplement 25:77-81.

${ }^{17}$ Raimondi AJ, Soare P. Intellectual development in shunted hydrocephalic children. Am J Dis Child 1974; 127:664-671.

${ }^{18}$ Hammock MK, Milhorat TH, Baron IS. Normal pressure hydrocephalus in patients with myelomeningocele. Dev Med Child Neurol 1976;Supplement 37:55-68.

19 Prigatano GP, Zeiner HK, Pollay M, Kaplan RJ. 
Neuropsychological functioning in children with shunted uncomplicated hydrocephalus. Child's Brain 1983; 10: 112-20.

${ }^{20}$ Di Rocco C, McLone DG, Shimoji T, Raimondi AJ.
Continuous intraventricular cerebrospinal fluid pressure recording in hydrocephalic children during wakefulness and sleep. J Neurosurg 1975;42:683-9. 